\title{
Prevalence and Management Practices of Low Back Pain Among Commercial Motorcyclists in Ilesa Southwest, Nigeria
}

\author{
Olorunfemi Akinbode Ogundele ${ }^{1,{ }^{*}}$, Olusegun Temitope Afolabi ${ }^{2}$, Funmito Omolola Fehintola ${ }^{3}$, \\ Abimbola Olorunsola ${ }^{4}$, Alex Adelosoye ${ }^{4}$ \\ ${ }^{1}$ Department of Community Health and Primary Care, State Specialist Hospital, Ondo City, Nigeria \\ ${ }^{2}$ Department of Community Health, Obafemi Awolowo University, Ile-Ife, Nigeria \\ ${ }^{3}$ Department of Community Medicine, Bowen University Teaching Hospital, Ogbomoso, Nigeria \\ ${ }^{4}$ Department of Family Medicine, State Specialist Hospital, Ondo City, Nigeria
}

\section{Email address:}

femiaoo@yahoo.com (O. A. Ogundele), temitopesegun@yahoo.com (O. T. Afolabi), funmitoabioye@yahoo.com (F. O. Fehintola), bimoriji@yahoo.com (A. Olorunsola), adelosoyealex@gmail.com (A. Adelosoye)

${ }^{*}$ Corresponding author

\section{To cite this article:}

Olorunfemi Akinbode Ogundele, Olusegun Temitope Afolabi, Funmito Omolola Fehintola, Abimbola Olorunsola, Alex Adelosoye. Prevalence and Management Practices of Low Back Pain Among Commercial Motorcyclists in Ilesa Southwest, Nigeria. Science Journal of Public Health. Vol. 5, No. 3, 2017, pp. 186-191. doi: 10.11648/j.sjph.20170503.15

Received: June 10, 2016; Accepted: July 29, 2016; Published: March 20, 2017

\begin{abstract}
Commercial motorcycling is fast becoming a recognised occupational group especially among the young people in Nigeria. Work-related Low back pain (LBP) may not be uncommon among them. This study assessed the prevalence and management practices of Low back pain among commercial motorcyclists in Ilesa Southwest, Nigeria. The study was a descriptive cross-sectional study. A systematic random sampling technique was used to select the required study subjects. Quantitative data collection method was employed. Data analysis was done using SPSS version 20.0. All the 393 respondents were male, $64.1 \%$ had secondary education. The mean age of respondent was $31.3(\mathrm{SD} \pm 4.5)$ years and the mean monthly income was 22,400 (SD $\pm 10,700)$ Nigerian naira. Fifty-four percent were full-time commercial motorcyclist. About $41 \%$ reported ever having LBP while $23 \%$ had LBP in the last 7 days prior to the study. Only $5.9 \%$ had ever been hospitalised because of LBP. Statistically, significant association exist between LBP and age of respondent $(p<0.001)$, the length of years as a commercial motorcyclist $(\mathrm{p}<0.016)$, sitting position on the motorcycle and working full time as a commercial motorcyclist $(\mathrm{p}<0.001)$. This study concluded that LBP is prevalent among commercial motorcyclist. There is a need for enlightenment programmes on how to avoid or possibly reduce the risk of LBP.
\end{abstract}

Keywords: Low Back Pain, Commercial Motorcyclists, Prevalence

\section{Introduction}

Low back pain (LBP) is one of the principal complaints by workers in the various occupations. It's a major health problem affecting not only the workforce but also the general populace. [1] The prevalence of LBP is related to the type of occupations such as driving, riding, manual handling and occupations that involve a lot of improper body movements. [1] It is a recognised societal problem from both a disablement and economic perspective, with costs exceeding that of coronary artery disease, respiratory infections, and diabetes. [2] LBP is reported to have a lifetime prevalence of up to $75 \%$ and is one of the most common conditions for which individuals seek medical care. [2] It is estimated that between $40 \%$ and $85 \%$ of people with LBP consults health care professionals about their pain. [3] It is frequently stated that a majority of LBP cases will resolve independent of intervention but recent data indicate that many cases progress to chronicity. [3] Occupation-related factors are the most important risks associated with LBP. [4] More than $80 \%$ of 
the population will experience an episode of LBP at some time during their lives. [5] The modifiable risk factors for LBP include a sedentary lifestyle, obesity, tobacco smoking and drug dependence. [6] Other modifiable factors are occupation-related: poor posturing, prolonged sitting, twisting, bending, stooping and lifting of heavy loads. The Expert Group on the Global Burden of disease Study showed that LBP is among the top ten high burden diseases and injuries, with disability-adjusted life years (DALYs) higher than that of Human immunodeficiency syndrome (HIV), road injuries, tuberculosis, lung cancer, chronic obstructive pulmonary disease and preterm birth complications. [7]

Commercial motorcycling is a fast evolving occupational group in Nigeria. The country alone has eight million registered commercial motorcyclists [8] thus constituting a major occupational group. Commercial motorcycling may be categorised as a high-risk job due to a variety of physical and psychological hazards associated with it. These hazards include inappropriate sitting posture, irregular helmet use, physical and psychological stress, failed road portions, poor compliance with road safety rules and overloading of motorcycles. Considering also that the original design of motorcycles was not with commercial intent, the risk for LBP might be more common than envisaged in this occupational group. With the vast majority of communities in Nigeria and sub-Sahara Africa using it for commercial purposes because of the poor transport system and bad road network, there is a need to assess the health implication of such activity. Very few studies have been done on the prevalence and risk for LBP among commercial motorcyclists in Nigeria. Most of the studies found were among occupational bus drivers, however, a study among commercial motorcyclists done in kano, Northwest Nigeria found a prevalence of thirty-six percent. [9] Assessing the prevalence, and management practices for LBP among commercial motorcyclists in Nigeria can assist in the formulation of intervention programmes for this fast growing occupational group not just in Nigeria but in sub-Sahara Africa as a whole. This study was conducted to determine the prevalence and management practices of LBP among commercial motorcyclists in Ilesa Southwest, Nigeria.

\section{Materials and Methods}

\subsection{Study Setting and Population}

The study was a descriptive, cross-sectional study carried out in Ilesa East Local Government Area (LGA) in Osun state Southwest, Nigeria. It has an estimated population of a little above 106,000 people. [10] Commercial motorcycle riding is a major means of transport in the local government area in both the rural and urban communities. A local branch of the national association of commercial motorcyclists called Amalgamated Commercial Motorcycle Owners and Riders Association of Nigeria (ACOMORON) exists in the LGA. They are a recognised occupational group both within the LGA and the nation at large. The registered members work on either full time or part time basis. The study population was commercial motorcyclists in Ilesa East LGA. Included in the study were commercial motorcyclists registered with the association while non-registered and nonconsenting motorcyclists were excluded.

\subsection{Sample Size and Sampling Technique}

The sample size was determined using the formula for simple prevalence studies with a reported prevalence of LBP of 36\% [9] and level of precision (0.05). A minimum of 354 respondents was determined. This was however increased to 393 after adjusting the sample size to allow for a nonresponse rate of $10 \%$.

The selection of the 393 respondents was by systematic random sampling technique. The sample frame was determined by obtaining the register of members of the association from the secretariat of ACOMORON Ilesa East chapter. The association had about 1494 registered members from the two units of the association in the LGA. The sampling interval was determined by dividing the total number of the members by the required sample size. Whenever an eligible member decline or is not available for interview the next available commercial motorcyclist was selected for the interview.

\subsection{Data Collection Technique}

Data collection techniques employed the use of a structured pretested interviewer-administered questionnaire. The questionnaire was designed to obtain information related to all the objectives and was designed using information from the literature. [11, 12] The questionnaire was assessed by an orthopaedic surgeon to ensure that essential information's were included. Questionnaire pre-test was done to ascertain validity by administering the questionnaire to 20 commercial motorcyclists not included in the study. Feedback from the pre-test was used for necessary modification. The Weight in kilogramme $(\mathrm{Kg})$ and height in metres $(\mathrm{m})$ of the respondents was also measured to determine the Body mass index (BMI) of participants. The BMI is defined as the weight in $\mathrm{Kg}$ divided by height in metres squared.

\subsection{Ethical Clearance}

The local government authority reviewed the study protocol and gave permission for the study. Informed verbal consent was obtained from each motorcyclist after explaining the purpose and benefits of the study.

\subsection{Operational Definitions}

For the purpose of this study, a full-time commercial motorcyclist was defined as a motorcyclist working for 8 hours per day, over 40 hours per week and at least 6 months of the year, while a part-time commercial motorcyclist is one that did not fulfil the above criteria.

LBP in this study was defined as pain occurring in the lumbosacral region below the 12th rib and above the gluteal folds. 
Prevalence of LBP is defined as ever having LBP since being a commercial motorcyclist.

Point prevalence of LBP in this study was defined as the presence of LBP within the last 7 days of study.

One year prevalence or 12 months prevalence was defined as reporting LBP in the last 12 months prior to the study.

\subsection{Statistical Analysis}

Data was entered and analysed using SPSS version 20.0 (Armonk, NY: IBM Corp.). Descriptive analysis such as frequencies, means, and standard deviation was used, among others, for the socio-demographic characterization of the participants and other relevant variables (age, education, marital status etc.). Further analysis of variables of interest was done using chi-square test of association. $\mathrm{P}<0.05$ was used to define statistical significance.

\section{Results}

Three hundred and ninety-three commercial motorcyclists participated in the study. All were males and majority had secondary education (64.1\%). Approximately Forty-four percent of respondents were aged between 21-30 years. The mean age was $31.3(\mathrm{SD} \pm 4.5)$ years. Majority of the respondents $(57.0 \%)$ were married. Forty-two percent earn between 10,000-20,000 Nigerian naira per month with a mean income of $22.400(\mathrm{SD} \pm 10.700)$ naira. They were mostly of Yoruba $(85.2 \%)$ tribe and majorly Christians (76.3\%). [Table 1].

Table 1. Socio demographic characteristics Respondents.

\begin{tabular}{|c|c|c|}
\hline Variable & Frequency $N=393$ & Percentage (\%) \\
\hline \multicolumn{3}{|l|}{ Educational status } \\
\hline No Education & 57 & 14.5 \\
\hline Primary Education & 49 & 12.5 \\
\hline Secondary Education & 252 & 64.1 \\
\hline Tertiary Education & 35 & 8.9 \\
\hline \multicolumn{3}{|l|}{ Marital Status } \\
\hline Married & 224 & 57.0 \\
\hline Not married & 169 & 43.0 \\
\hline \multicolumn{3}{|l|}{ Religion } \\
\hline Christianity & 300 & 76.3 \\
\hline Islam & 86 & 21.9 \\
\hline Others & 7 & 1.8 \\
\hline \multicolumn{3}{|l|}{ Age (years) } \\
\hline$<20$ & 112 & 28.5 \\
\hline $21-30$ & 172 & 43.8 \\
\hline$\geq 31$ & 109 & 27.7 \\
\hline \multicolumn{3}{|l|}{ Ethnicity } \\
\hline Yoruba & 335 & 85.2 \\
\hline Ibo & 30 & 7.6 \\
\hline Hausa & 3 & 0.8 \\
\hline \multicolumn{3}{|c|}{ Average monthly Income } \\
\hline$<10,000$ & 46 & 11.8 \\
\hline $10.000-20,000$ & 166 & 42.2 \\
\hline $21,000-30,000$ & 107 & 27.2 \\
\hline$>31,000$ & 74 & 18.8 \\
\hline
\end{tabular}

Approximately $55 \%$ had worked as commercial motorcyclist for more than 5 years. The majority (54.2\%) were full-time commercial motorcyclists. Among the full- time commercial motorcyclist, $93.4 \%$ worked for an average of 8 hours or more per day a week prior to the study compared to $54.4 \%$ of the part-time motorcyclist. [Table 2] About $(40.7 \%)$ of the respondents had experienced LBP in the past while $22.6 \%$ had LBP in the last 7 days prior to the study. Thirty percent of respondents had LBP in the last 12 months. [Table 2]

Table 2. Work history and prevalence of LBP among commercial motorcyclist $(N=393)$.

\begin{tabular}{|c|c|c|}
\hline Variable & Frequency & Percentage (\%) \\
\hline \multicolumn{3}{|c|}{ Years of work as commercial motorcyclist (years) } \\
\hline$<1$ & 70 & 17.8 \\
\hline $2-5$ & 106 & 27.0 \\
\hline$>5$ & 217 & 55.2 \\
\hline \multicolumn{3}{|c|}{ Commercial motorcyclist type } \\
\hline Full- time & 213 & 54.2 \\
\hline Part-time & 180 & 45.8 \\
\hline \multicolumn{3}{|c|}{ Full time motorcyclist work hour/ day ${ }^{* *}$} \\
\hline$<7$ hours & 14 & 6.6 \\
\hline$>8$ hours & 199 & 93.4 \\
\hline \multicolumn{3}{|c|}{ Part time motorcyclist work hour/day ${ }^{*}$} \\
\hline$<7$ hours & 82 & 45.6 \\
\hline$>8$ hours & 98 & 54.4 \\
\hline \multicolumn{3}{|c|}{ Ever had LBP } \\
\hline Yes & 160 & 40.7 \\
\hline No & 233 & 59.3 \\
\hline \multicolumn{3}{|c|}{ LBP in the last 7 days } \\
\hline Yes & 89 & 22.6 \\
\hline No & 304 & 77.4 \\
\hline \multicolumn{3}{|c|}{ LBP in last 12 months } \\
\hline Yes & 118 & 30.0 \\
\hline No & 275 & 70.0 \\
\hline \multicolumn{3}{|c|}{ Ever been Hospitalised for LBP } \\
\hline Yes & 23 & 5.9 \\
\hline No & 370 & 94.1 \\
\hline
\end{tabular}

**Average work hour for full-time motorcyclist a week prior to study *Average work hour for part-time motorcyclist a week prior to study

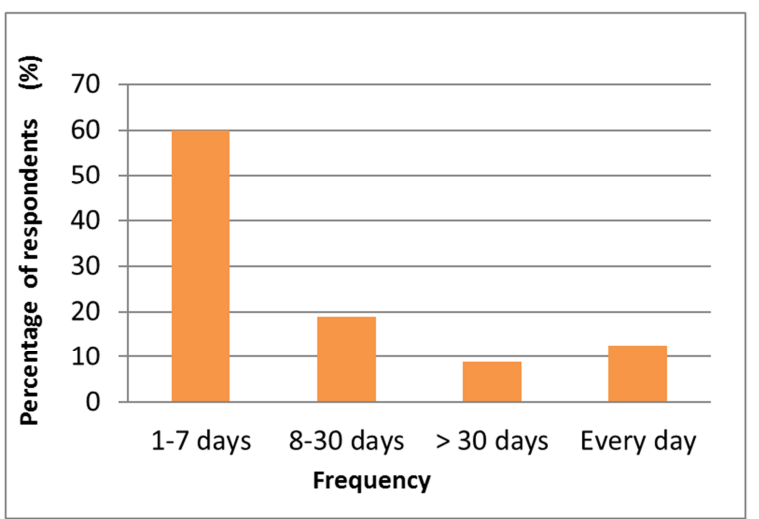

Figure 1. Frequency of $L B P$ episodes among respondent who reported $L B P$ $n=160$.

Among participants who reported having ever had LBP. Sixty percent indicated that they experienced LBP at least once in a week, 19\% within 4 weeks, and $9 \%$ at least once in a month while $13 \%$ had it daily [Figure 1].

Bivariate analysis of the association between selected socio-demographic factors and low back pain among the respondents revealed that significant association exist 
between the age of respondents and LBP $\left(\chi^{2}=16.34\right.$, $\mathrm{p}<0.001)$. A higher proportion of those aged 31 years and above $(56.9 \%)$ had LBP compared to those 30 years and below $(34.5 \%)$. Sitting position on a motorcycle also had a significant statistical association with LBP $\left(\chi^{2}=10.73\right.$ $\mathrm{p}=0.001$ ), with a greater proportion of those who bend forward while riding $(77.8 \%)$ having LBP compared to $38.9 \%$ among those who sit upright. The length of years as a commercial motorcyclist $\left(\chi^{2}=5.79\right.$,

$\mathrm{p}<0.016$ ) and working as a full-time commercial motorcyclist $\left(\chi^{2}=72.37, \quad \mathrm{p}<0.001\right)$ was also significantly associated with having LBP [Table 3]. Only one commercial motorcyclist among the 160 that had LBP had BMI category $\geq 25 \mathrm{~kg} / \mathrm{m}^{2}$. No statistically significant association between LBP and BMI was found $\left(\chi^{2}=2.06 \mathrm{p}=0.151\right)$. Co-morbidity $\left(\chi^{2}=3.54, \mathrm{p}=0.060\right)$ and work hour per day $\left(\chi^{2}=2.86 \mathrm{p}=0.090\right)$ were not statistically associated with LBP although a higher a proportion of those who worked for more than 8 hours per day $(40.1 \%$ ) had LBP compared with $33.3 \%$ in those who worked for 7 hours and less [Table 3].

Table 3. Factors associated with Low back Pain among commercial motorcyclist.

\begin{tabular}{|c|c|c|c|}
\hline \multirow{2}{*}{ Variable } & \multicolumn{2}{|c|}{ Low Back Pain $\mathrm{N}=393$} & \multirow{2}{*}{ Statistical Indices } \\
\hline & Yes n $(\%)$ & Non $(\%)$ & \\
\hline \multicolumn{4}{|l|}{ Age (years) } \\
\hline$\leq 30$ & $98(34.5)$ & $186(65.5)$ & \multirow{2}{*}{$\chi^{2}=16.34 \mathrm{p}<0.001$} \\
\hline$\geq 31$ & $62(56.9)$ & $47(43.1)$ & \\
\hline \multicolumn{4}{|c|}{ Length of work as commercial motorcyclist (years) } \\
\hline$<5$ & $60(34.1)$ & $116(65.9)$ & \multirow{2}{*}{$\chi^{2}=5.79 p<0.016$} \\
\hline$>5$ & $100(46.1)$ & $117(53.9)$ & \\
\hline Full time & $128(60.1)$ & $85(39.9)$ & \multirow{3}{*}{$\chi^{2}=72.37 \mathrm{p}<0.001$} \\
\hline Part time & $32(17.8)$ & $148(82.2)$ & \\
\hline \multicolumn{3}{|c|}{ Work hour/ day a week prior to study } & \\
\hline$<7$ hours & $32(33.3)$ & $64(66.7)$ & \multirow{2}{*}{$\chi^{2}=2.86 \mathrm{p}=0.090$} \\
\hline$>8$ hours & $128(40.1)$ & $169(56.9)$ & \\
\hline \multicolumn{4}{|l|}{ Sitting position on motorcycle } \\
\hline Bending & $14(77.8)$ & $4(22.2)$ & $\chi^{2}=10.73 \mathrm{p}=0.001^{*}$ \\
\hline \multicolumn{4}{|l|}{ Body Mass Index category } \\
\hline$<25$ (normal weight and below) & $159(41.2)$ & $227(58.8)$ & \multirow{3}{*}{$\chi^{2}=2.06 \mathrm{p}=0.151^{*}$} \\
\hline$\geq 25$ (overweight and above) & $1(14.3)$ & $6(85.7)$ & \\
\hline \multicolumn{3}{|l|}{ Co-morbidity $^{* *}$} & \\
\hline Yes & $3(16.7)$ & $15(83.3)$ & \multirow{2}{*}{$\chi^{2}=3.54, p=0.060^{*}$} \\
\hline No & $157(41.9)$ & $218(58.1)$ & \\
\hline
\end{tabular}

*Yates correction, **co-morbidity (Obesity, Hypertension, diabetes)

Common management practices engaged in by the respondents to alleviate their LBP are as in table 4. Most of the commercial motorcyclist use self-prescribed drug $(32.5 \%)$, herbal preparation $(25 \%)$, hot fermentation $(9.3 \%)$ and traditional medicine $(1.9 \%)$ to alleviate their LBP while about $26.3 \%$ of respondents sought hospital treatment.

Table 4. Common practices of LBP engaged in by commercial motorcyclist.

\begin{tabular}{lll}
\hline Variable & Frequency $\mathbf{N = 1 6 0}$ & Percentage (\%) \\
\hline Self-prescribed drugs & 52 & 32.5 \\
Hospital/ Health Facility & 42 & 26.3 \\
Hot Fermentation & 15 & 9.3 \\
Herbal Medicine & 40 & 25.0 \\
Traditional medicine & 3 & 1.9 \\
Others & 8 & 5.0 \\
\hline
\end{tabular}

\section{Discussion}

LBP is a well-recognised cause of morbidity in the industrialised world, the general population and occupational settings. The prevalence of LBP will vary depending on the definition and the population studied. In this study, the prevalence of LBP among commercial motorcyclists was approximately forty-one percent. This result is similar to findings from a study in kano, Nigeria among commercial motorcyclists which reported a prevalence of thirty-six percent. [10] A study among office workers in Ibadan found a similar prevalence rate. [12] The prevalence in this study is, however, lower than that found by akinpelu et al in another study among occupational drivers in Ibadan. [13] This difference may not be unconnected with the mechanical difference between a vehicle and a motorcycle and the long duration of exposure to whole body vibration by the occupational drivers, unlike the commercial motorcyclist.

This study also found the point prevalence of low back pain to be about twenty-two percent. This finding is comparable to that of omokodion et al [13] from Ibadan although the study was among office workers, unlike this study. Furthermore, significant statistical associations exist between having LBP and age of respondents, sitting position on the motorcycle, working as a full-time commercial motorcyclist and length of years as a commercial motorcyclist. Bending forward while riding was associated with LBP in a greater proportion of participant than sitting upright while riding. There might, therefore, be a need to educate commercial motorcyclist on appropriate sitting position while riding. In this study, a higher proportion of full-time commercial motorcyclist reported LBP than the part 
time commercial motorcyclist. This may be related to the numbers of hours spent riding because a full-time commercial motorcyclist works for more than 8 hours per day and 40 hours per week. Riding as a task involves prolonged sitting, a fixed posture and vibration, any of which could directly lead to musculoskeletal trouble. Commercial motorcycle riding involves prolong sitting and frequent exposure to vibration and thus might explain the increase occurrence of LBP among full-time commercial motorcyclists. With longer years of riding experience, the occurrence of LBP was found to be higher. These findings agree with Nicole's study which reported years of driving experience as significantly associated with the development of LBP [14] and that those without reported experience of pain at the time of the study have the possibility of developing pain after riding for long years.

The study found that the most common management practice engaged in by the commercial motorcyclist in alleviating their LBP was the use of self-prescribed drugs. This is in keeping with findings by akinpelu et al [13] and also Haetzman et al [15] who reported that non-prescription medication is taken by a high number of individuals with chronic pain. This, however, contradicts findings by hilman et $a l$. [16] This study further found that only $26.3 \%$ of those that reported LBP sought care from health practitioners because of the pain. This shows that only a few commercial motorcyclists sought medical attention in managing their pain. This is contrary to findings by Chris and Amanda who reported that higher percentage of people with musculoskeletal pain reported at health centres. [17] Their study, however, was among occupational drivers and not among commercial motorcyclists. The low level of care seeking from health professional among the commercial motorcyclists might be due to lack of information on the availability of effective treatments for LBP or an assessment of their symptoms as not been severe enough to be reported. Use of herbal medicine was very common among the respondents; this may be linked to their closeness to herbal medicine sellers who hawk their goods at different bus stops or bike stations. This finding is similar to the study of Palinkas and Kabongo who reported that musculoskeletal pain was the most common health problem associated with complementary and alternative medicine use. [18] Although the focus of this study was not to estimate the level of education of commercial motorcyclists, a high proportion (64\%) attained a secondary level of education and thus a lack of education might not explain their poor health seeking behaviour and preference for herbal medicine. A possible explanation for the poor health seeking behaviour might rather be a lack of appropriate health information. This is in keeping with findings from some other studies [18] which revealed that level of education was inversely associated with the use of traditional remedies of complementary and alternative medicine.

\section{Conclusion}

This study concluded that the prevalence of LBP is high among commercial motorcyclists with various un-orthodox management options employed by them in alleviating their pain. There is therefore a need to empower commercial motorcyclists with regular, correct and appropriate health information to improve their quality of life with regards to LBP and its management.

\section{Acknowledgement}

We appreciate all commercial motorcyclists who participated in the study

\section{References}

[1] Shirado O IT, Kaneda K, Strax TE Flexion-relaxation phenomenon in the back muscles. A comparative study between healthy subjects and patients with chronic low back pain. Am J Phys Med Rehabil. 1995; 74, 139-44.

[2] McKenzie RA, May S. The Lumbar Spine: Mechanical Diagnosis and Therapy. 2nd ed. Waikanae, New Zealand: Spinal Publications, 2003.

[3] Carey TS, Evans A, Hadler N, Kalsbeek W, McLaughlin C, Fryer J. Care-seeking among individuals with chronic low back pain. Spine. 1995; 20: 312-317.

[4] Vandergrift JL, Gold JE, Hanlon A, Punnett L. Physical and psychosocial ergonomic risk factors for low back pain in automobile manufacturing workers. Occup Environ Med. 2012; 69 (1): 29-34.

[5] Freburger JK, Holmes GM, Agans RP, et al. The rising prevalence of chronic low back pain Arch Intern Med. 2009; 169 (3): 251-258.

[6] Vindigni D, Walker BF, Jamison JR, Da Costa C, Parkinson L, Blunden S. Low back pain risk factors in a large rural Australian Aboriginal community. An opportunity for managing co-morbidities? Chirop \& Osteopat. 2005; 13: 21.

[7] Mohammad A. Years lived with disability (YLDs) for 1160 sequelae of 289 diseases and injuries 1990-2010: a systematic analysis for the Global Burden of Disease Study 2010. Lancet. 2012 Dec 15; 380 (9859): 2163-96. doi: 10.1016/S01406736(12)61729-2. Erratum in: Lancet. 2013 Feb 23; 381 (9867): 628.

[8] NAN. Nigeria has eight million registered okada ridersAssociation President. Premium Times Available from www.premiumtimes,ng,com [newspaper online]. 2014 April 11 [cited 2015 May 22].

[9] Lawal IU, Tahir SA, Ahmad RY. Prevalence of Low Back Pain Complaints among Commercial Motorcyclists in Kano, NorthWest, Nigeria. Niger Med Pract. 2009: Vol 56, No 1-2.

[10] Osun State. Nigeria directory. National Bureau of Statistics Census 2006 report. www.nigerianstat gov.ng.

[11] National Institute of Arthritis and Musculoskeletal and Skin Diseases. Handout on health: back pain. Avaliable from www.niams.nihs.gov 2012. [page on internet] [cited 2014 Dec 3].

[12] Omokhodion FO, Sanya AO. Risk factors for low back pain among office workers in Ibadan, Southwest, Nigeria. Occupational Medicine. 2003; 53 (4): 287-289. 
[13] Akinpelu AO, Oyewole O O, Odole AC, Olukoya RO. Prevalence of Musculoskeletal Pain and Health seeking Behaviour among Occupational Drivers in Ibadan, Nigeria Afr. J. Biomed. Res. 2011; 1 (4): 89-94.

[14] Nicole M: Paper presented at the ECOHSE 2000 symposium, Lithuania. 2000.

[15] Haetzman M, Elliott AM, Smith BH, Hannaford P, Chambers WA. Chronic pain and the use of conventional and alternative therapy. J Fam Pract. 2003; 20 (2): 147-154.
[16] Hillman M, Wright A, Rajaratnam G, Tennant A, Chamberlain MA. Prevalence of low back pain in the community: implications for service provision in Bradford, UK. J Epidemiol Community Health. 1996; 50: 347-352.

[17] Chris JM, Amanda C de C Williams. ABC of psychological medicine. Musculoskeletal, BMJ. 2000: 325: 534-537.

[18] Palinkas LA, Kabongo ML. The Use of Complementary and Alternative Medicine by Primary Care Patients. J Fam Pract. 2000; 49: 1121-113. 